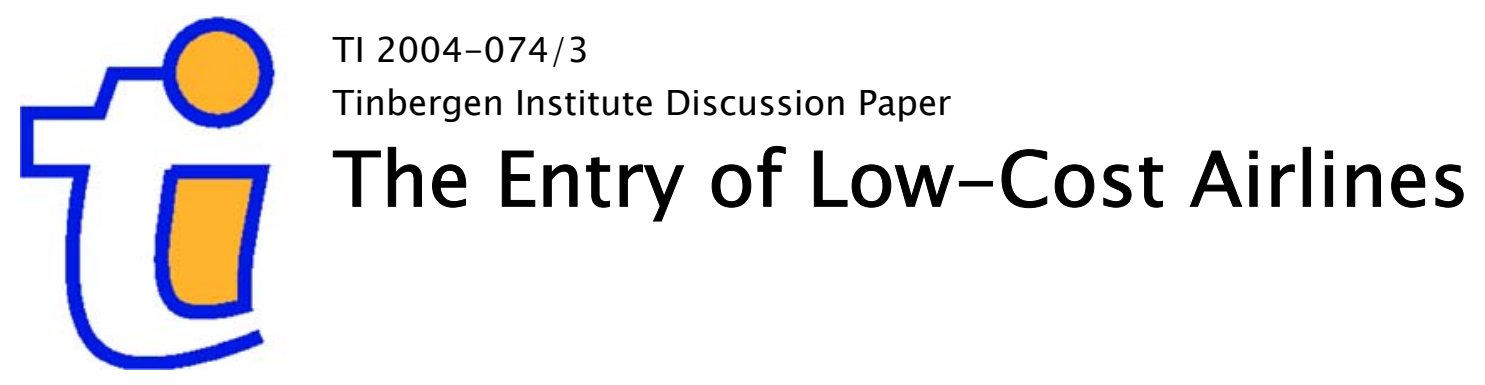

\author{
Marco Alderighir \\ Alessandro Cento 2 \\ Peter Nijkamp3 \\ Piet Rietveld 3
}

1 CERTeT, Bocconi University, Milan,

${ }^{2}$ KLM Royal Dutch Airlines, Revenue Management Dept, Milan,

${ }^{3}$ Faculty of Economics and Business Administration, Vrije Universiteit Amsterdam, and Tinbergen Institute. 


\section{Tinbergen Institute}

The Tinbergen Institute is the institute for economic research of the Erasmus Universiteit Rotterdam, Universiteit van Amsterdam, and Vrije Universiteit Amsterdam.

Tinbergen Institute Amsterdam

Roetersstraat 31

1018 WB Amsterdam

The Netherlands

Tel.: $\quad+31(0) 205513500$

Fax: $\quad+31(0) 205513555$

Tinbergen Institute Rotterdam

Burg. Oudlaan 50

3062 PA Rotterdam

The Netherlands

Tel.: $\quad+31(0) 104088900$

Fax: $\quad+31(0) 104089031$

Please send questions and/or remarks of nonscientific nature to driessen@tinbergen.nl.

Most TI discussion papers can be downloaded at http://www.tinbergen.nl. 


\title{
The Entry of Low-Cost Airlines: Price Competition in the European Airline Market
}

\author{
Marco ALDERIGHI, CERTeT - Bocconi University, Milan, Italy \\ e-mail: marco.alderighi@uni-bocconi.it
}

\begin{abstract}
Alessandro CENTO, KLM Royal Dutch Airlines, Revenue Management Dept, Milan, Italy,e-mail: alessandro.cento@klm.com
\end{abstract}

Peter NIJKAMP, Free University, Amsterdam, The Netherlands

e-mail: pnijkamp@,feweb.vu.nl

Piet RIETVELD, Free University, Amsterdam, The Netherlands

e-mail: prietveld@,feweb.vu.nl

This paper investigates the response of full service carriers (FSCs) to the entry of low-cost carriers (LCCs). We develop a model of airline competition, which accommodates various market structures, some of which include low-cost players. Using data on published airfares of Lufthansa, British Airways, Alitalia and KLM for the main city-pairs from Italy to the rest of Europe, our statistical modelling results confirm the conclusions of the theoretical model. Competition among FSCs appears to affect the price levels of business and leisure segments asymmetrically. In contrast, competition with LCCs reduces the fares of FSCs in all classes proportionally.

Keywords: Pricing strategies, yield management, low-cost carriers, European airline market. JEL Classification: D43, L15, L93. 


\section{Introduction}

In recent years, the European aviation sector has exhibited impressive dynamics. The airline market has gone through a drastic change on both the supply and the demand side. Different to other industries, the driving forces governing the changes do not depend mainly on technological factors, but on developments in the legal, institutional and cultural domains. Legal and institutional aspects have clearly affected the structure of the market, while cultural forces have influenced spatial mobility and its characteristics. This paper presents a concise analysis of the main changes in the sector in order to understand the emergence of low-cost carriers in Europe.

On the supply side, we observe that only a few industries have faced changes as deep as those that have occurred in the airline industry in the past 20 years. Over this time period, the industry has evolved from a system of long established state-owned carriers operating in a regulated market to a dynamic, free-market industry. Before the deregulation, only one or two flag carriers operated the European routes, with airfares being regulated by state bilateral agreements. The European deregulation took place about 10 years after the US deregulation. Three airline policy 'packages' were agreed in 1988, 1990 and 1993, and full deregulation came into force in 1997. The Third Package ${ }^{1}$ was the most important one, as by then, pricing capacity and access were fully deregulated. Within the EU, airlines can now operate between two other member countries via their home country (the "sixth freedom" from the Chicago Convention) and even operate domestic flights within other European member countries (the "seventh freedom" or cabotage right).

The process of deregulation and the subsequent process of privatisation has induced important changes in the structure of the airline market. On the one hand, many carriers have signed alliances to exploit economies of scale and scope and to optimise their network operations. On the other hands, the airlines network has evolved from a point-to-point system to a hub-and-spoke-system, and, finally, with the international alliances, to the multi-hub and spokes system. Sophisticated yield management techniques were developed on in order to control the aircraft availability and to provide an even more differentiated product by offering in-flight entertainment, fast check-in, VIP waiting lounges, ground services, etc. Therefore, the old national carriers are called full service carriers (FSC).

\footnotetext{
${ }^{1}$ See, e.g., Starkie (2002), Chang and Williams (2002).
} 
The low-cost carrier, (hereafter abbreviated as LCC) is defined as an airline designed to have a competitive advantage in terms of costs over FSCs. An LCC relies on a very simple firm organisation and logistic principles. In contrast to the hub-and-spoke configuration developed by traditional carriers, the LLC offers point-to-point connections from secondary airports, i.e., smaller airports -such as London Luton- that are less expensive in terms of landing tax and handling fee than bigger airports such as Heathrow or Manchester. Ryanair, for example, used Dublin and Stansted as its central airports in 1999. Recently, Ryanair developed more hubs in Stockholm, Milan Orio al Serio and Rome Ciampino. The fleet generally includes one type of aircraft that operates more hours a day than the traditional carriers in order to maximise the utilisation on a daily basis. The LLC product is not differentiated, and has no frills service: no lounges at airports, no choice of seats, no newspaper, no catering, no frequent-flyer program, no refund and no possibility to rebook with other airlines. Distribution is as simple as possible, by making use of Internet direct sales and with electronic tickets. The LCCs experienced a fast growth after 1999 and did not suffer as much from the crisis in the air transport industry after September 11, 2001, because the low fare levels were still attracting many passengers, and because low-cost carriers were not yet operating in politically sensitive regions.

In order to understand why low cost carriers have managed to expand in the airline market, it is also important to consider structural developments on the demand side. In general, the process of internationalisation and globalisation has increased not only the mobility of goods, but also of people. Trade agreements and an expansion of cargo transport have contributed to an increase in -or are related to- the high mobility of business travellers ${ }^{2}$. Also, the behaviour of tourists has drastically changed. Travellers seem to be shifting to multiple and short holidays as opposed to traditional long stays, while also the loss of the glamour involved with flying -and hence lower service levels- is accepted by many travellers nowadays.

This paper focuses on the response in term of prices by FSCs to the entry of LCCs. In Section 2, we present some basic concepts concerning product differentiation and pricing techniques in the airline industry. In Section 3, we propose a theoretical framework of airline competition, which accommodates different market structures. In the monopoly case (Section 3.2), we analyse the behaviour of an FSC, and use this case as a benchmark. In the symmetric case (Section 3.3) and asymmetric (Section 3.4) duopoly case we study the competition between two FSCs, and between an FSC and an LCC, respectively. The model is finally 
extended to the case of asymmetric oligopoly (Section 3.5), where the interaction among two FSCs and an LCC is considered. The overall results of the model for each market case are then compared and summarised.

We offer an empirical test of our theoretical model in Section 4. After presenting the main variables of the database (Section 4.1), we verify some of the theoretical outcomes by providing an estimation of the impact of traditional competitors and low-cost competitors on the fares of FSCs (Section 4.2). We use monthly data on the airfares of Lufthansa, British Airways, Alitalia and KLM for the top-12 city-pairs from Italy to Europe (April 2001-July 2003). Contrary to what is done in other research projects, we do not consider average prices, but perform an analysis on the basis of 8 different classes of airfares. A first finding is that competition among traditional carriers affects the price levels of business and leisure segments asymmetrically. In moving from a monopoly to a symmetric duopoly, the business fares appear to decline more than the economy fares. The second interesting result is that LCCs affect all the airfares uniformly.

Section 5 makes some concluding remarks and suggestions for further research.

\section{Yield Management}

Market factors such as demand fluctuations, consumer heterogeneity, and uncertainty about the traveller' departure date or even their the destination, combined with a limited aircraft capacity and the very perishable nature of the product (the unsold seats cannot be used as soon as a flight departs), make the setting of airfares and the allocation of aircraft seats a complex process. Over the past years carriers have adopted a set of techniques to allocate limited and highly perishable resources among differentiated consumers. These techniques are known as 'yield management' ${ }^{3}$ (or 'revenue management'). The goal of yield management is to maximise the revenue of a carrier operating in such a complex market environment. We identify two aspects of yield management. First, customers are heterogeneous in travel behaviour or willingness to pay, and thus firms have the opportunity to customise their product to fulfil the demand. Second, once the output is produced (availability of seats), costs can be considered sunk costs and therefore the yield maximisation problem coincides with profit maximisation ${ }^{4}$. We call traditional yield management the set of techniques that are usually adopted by the FSC. Traditional yield

\footnotetext{
${ }^{3}$ For a review of different yield management techniques, we refer to Weatherford and Bodily (1992).

${ }^{4}$ This explains why it is called revenue or yield management and notprofit management.
} 
management can be described by six simple principles: market segmentation, product differentiation, price setting, fences, availability control, and distribution. Traveller behaviour induces the FSC to segment the demand and offer a differentiated product by a wide variety of in-flight and ground services. Prices are set in relation to the different levels of quality requested by the travellers. In order to ensure that any segment of passengers purchases its required levels of quality, the FSC differentiates the product by applying fences. Product fences are rules that regulate the ticketing purchase and the conditions imposed on each traveller category. Examples of fences are ticket cancellation or travel date change penalties, purchase time limits, or minimum stay at the travel destination. In addition to the fences, adding extra services to the basic transport can differentiate the airline product (we have already mentioned some examples of services: in-flight entertainment, fast check-in, VIP waiting lounges, etc.). The different products are offered to the market through the aircraft reservation classes ${ }^{5}$. The reservation classes are created to reflect the market segmentation. One or more airfares are applicable to each class of reservation. By having discrete fare classes, the yield management system had to face the problem of forecasting the demand and then allocating the right number of seats of each class in order to optimise the revenue. This activity is called inventory control, and it is usually implemented for all flights operating between any combination of city-pairs of the network up to one year into the future. Nowadays, however, the hub-and-spoke networks are capable to generating thousands of origin and destination combinations and therefore the inventory control require the support of sophisticated computer systems. Moreover, the inventory control approach also requires the distribution system to be able to display the seat availability of each reservation class. The modern GDSs (global distribution systems) are indeed able to support such complex inventory control systems.

On the other hand we call the set of techniques used by the low cost carriers simplified yield management, which differs radically from traditional yield management with respect to two elements. Segmentation is only applied through time of booking and choice of flight. The passenger who wishes to pay lower prices must book early, or on the flights for which there is less demand ${ }^{6}$. The product is not differentiated: there are no additional services included in the

\footnotetext{
${ }^{5}$ Carriers label classes with capital letters. For example, the promotional classes of Alitalia are $\mathrm{O}$ and $\mathrm{N}$, while the ones of Lufthansa are $\mathrm{V}$ or $\mathrm{W}$. In the next section, we propose a class mapping in order to be able to compare them.

${ }^{6}$ LCCs modify the selling price of each flight as a function of the departure date. If a price is too low, the flight will fill up early and higher-yielding late-booking business will be turned away. On the contrary, if the price is too high, the flight is at risk of departing with empty seats.
} 
price, no drinks or food, no frequent flyers program or convenient airport, no VIP lounge or inflight services. The rules applied to the fares are removed, as no segmentation is applied: no Sunday rule, date limits, changes fee, and so on. Those factors make the inventory control of LCCs simpler to manage than FSCs. The distribution system can be implemented via the Internet so that passenger is able to compare prices as a function of date or time of departure. The simplified yield management techniques do not apply any explicit product differentiation, except for a dynamic pricing schedule based on the departure date, while traditional yield management chooses the best combination of fares and conditions for each passenger category (quality product) to each passenger category.

\section{Theoretical Framework}

\subsection{Prefatory remarks}

In this section we develop a theoretical model to analyse the airlines price competition. The framework is based on recent literature on product differentiation in oligopolistic markets ${ }^{7}$. Previous contributions such as Murphy (1977) Oren, Smith and Wilson, (1983) Calem and Spulber (1984) and Holmes (1989) assumed no interdependencies among markets, i.e. business travellers do not demand the leisure products and vice-versa. However, contrary to those authors, we follow the approach of Wilson (1993), Rochet and Stole (2002) and Dussein (2002) who developed a model with market interdependencies ${ }^{8}$. This approach is quite different from the traditional scheme, in that the firm's demand is not represented as a function of prices, but is expressed in terms of utility levels provided to consumers by the firms. In this set-up, Rochet and Stole proved that the assumption of interdependency does not affect the market equilibrium

\footnotetext{
${ }^{7}$ Other authors, .e.g. Carlton (1977) and Dana (1999a, 1999b) have focused on the complementary aspect, which involves price discrimination that concerns peak and off-peak pricing when demand is unknown.

${ }^{8}$ Many other authors have analysed this topic. Among these authors, it is worth, from a theoretical point of view, mentioning Ivaldi and Martimort (1994), Stole (1995), Armstrong (1996), Jamilton and Thisse (1997), Armstrong and Vickers (2001), Jensen (2001), Dussein (2002) and Valletti (2002). From an empirical point of view, it is worth mentioning Borestein (1985), Berry (1994), Borestein and Rose (1994), McManus (2001), Clerides (2003) and Macskási (2003).
} 
(both in terms of qualities and prices), when oligopolistic markets are characterised by symmetric firms ${ }^{9}$.

Our model differs from the pervious ones as it sets the problem in the traditional form (i.e. in terms of prices), but it takes into account the market interdependencies. This simplification is possible as we assume that qualities are exogenously determined like in traditional oligopolistic models. Hence, we arrive at our intermediate position between the traditional modelling approach and the one proposed by Wilson.

We assume that there are two types of firms: traditional firms (namely, $L$ or $R$ ), and low cost firms (namely, $S$ or $M$ ). They differ with regard to two aspects. A traditional firm can offer products of two different qualities: $q_{1}$ and $q_{2}, q_{1}<q_{2}$, with corresponding unit costs $c_{1}<c_{2}$. A low-cost firm can only provide products of quality $q_{1}$ with costs $c_{0} \leq c_{1}$. In other words, traditional firms can offer a full range of products but at higher cost, while low cost firms can offer a restricted range of products but at lower cost.

Consumers are vertically heterogeneous and form two markets: the strong market (business travellers with a high willingness-to-pay: namely, $t_{2}$ ) and the weak market (leisure travellers with a low willingness-to-pay: namely, $t_{1}$ ). The size of the weak market is $\mu_{1}=\mu$, and the size of the strong market is $\mu_{2}=1-\mu$. Both types of consumer appreciate quality, although the consumers belonging to the strong market are more interested in quality than the others. Let $u_{i l}=t_{i} q_{l}$ be the utility evaluation of a product of quality $l$ by consumer $i$. Hence, we assume that:

$u_{i 2}>u_{i 1}$ for $i=1,2$ and $u_{22}-u_{21}>u_{12}-u_{11}$.

Traditional firms design products of quality $q_{1}$ for the weak market, and products of quality $q_{2}$ for the strong market. In any case, since markets are interdependent, there can be diversion, i.e. a $t_{2}$-type consumer can be interested in a product designed for $t_{1}$. Let us call $p_{1 j}$ the price charged by firm $j$ for $q_{1}$, and $p_{2 j}$ the price for $q_{2}$. To avoid diversion, firm $j$ must

\footnotetext{
${ }^{9}$ Note that this result differs from that of the monopoly case, where the presence of interdependency affects the equilibrium (both in terms of quality and prices), (see Mussa and Rosen, 1978). On the
} 
choose $p_{1 j}$ and $p_{2 j}$, so that the net utility of $t_{2}$, when he/she buys $q_{2}$, is at least equal to his/her net utility when he/she buys $q_{1}$. This means in formal terms: $u_{22}-p_{2 j} \geq u_{21}-p_{1 j}$. Note that this inequality may also be written as:

$p_{2 j}-p_{1 j} \leq r$

where $r=u_{22}-u_{21}$. This condition is known as the 'incentive compatibility constraint ${ }^{\prime 10}$ (IC).

Consumers are also horizontally heterogeneous so that, ceteris paribus, some of them prefer to buy from firm $L$ and others from firm $R, S$ or $M$. In other words, consumers' preferences are heterogeneous with respect to the brand. Interpreting this in terms of spatial distribution of consumers, we can imagine that consumers are uniformly distributed on a unitary Hotelling (1929) segment and that firms are located at different points on the line. We normalise the consumer mass to 1 .

The unitary (transportation) cost of consuming a product, which differs horizontally from the consumer's ideal, one is $\sigma$. Taking all these things into account, the utility of a consumer of type $i$ located at $x$, who consumes a product of quality $l$ from firm $j$ located at $y_{j}$ is then equal to: $u_{i l}-p_{l j}-\sigma\left|x-y_{j}\right|$.

We will analyse four different situations:

1. Monopoly: one traditional firm $L$ on the market located at $y_{L}=0$;

2. Symmetric duopoly: two traditional firms on the market, namely $L$ and $R$, located at $y_{L}=0$ and $y_{R}=1$;

3. Asymmetric duopoly: one traditional firm $L$ and one low cost firm $S$, located, respectively, at $y_{L}=0$ and $y_{S}=1$;

4. Asymmetric oligopoly: two traditional firms $L$ and $R$ and one low cost firm $M$, located, respectively, at $y_{L}=0, y_{R}=1$ and $y_{M}=\frac{1}{2}$.

contrary, Alderighi (2004) shows that interdependency matters, when we consider market structures with asymmetric firms.

${ }^{10}$ The incentive compatibility constraint is said to be binding when a firm chooses the prices of high quality and low quality products in such a way that high willingness-to-pay consumers are indifferent to buying a high quality product at a high price and buying a low quality product at a low price. On the 
In this set-up, it is important to compute the consumer demand of firm $j=L, R, S, M$ in market $i$, i.e. the number of consumers of type $t_{i}$ that will buy from $j$. Let $d_{j}$ and $p_{l j}$ be, respectively, the distance of a selected consumer from firm $j$ and the prices charged by firm $j$ for a product of quality $l$. A consumer will buy a product of quality $l$ from $j \neq k$, if $u_{i l}-p_{l j}-\sigma d_{j}<u_{i l}-p_{l k}-\sigma d_{k}$, where $k=0, L, R, S$ and $M, p_{l k}$ and $d_{k}$ are, respectively, the price charged by and the distance from the competitor. When $k=0$, the inequality captures the decision of not buying, i.e. $p_{l 0}=u_{i l}, d_{0}=0$.

Assume $^{11}$ that there is no diversion, i.e., firms charge prices so that the incentive compatibility constraint of equation (2) is satisfied. So, the demand for a product of quality $q_{l}$ faced by the monopolist $L$ in the market $t_{i}$ with $l=i$ is:

$D_{i L}\left(p_{i L}\right)=\mu_{i} \mathrm{U}\left(\frac{u_{i i}-p_{i L}}{\sigma}\right)$

where $U$ is the cumulative uniform distribution with support $[0,1]$.

Now, in duopoly ${ }^{12}$, the demand for $L$ in the market $t_{i}$ is:

$D_{i L}\left(p_{i L}, p_{i k}\right)=\mu_{i} \mathrm{U}\left(\frac{1}{2}+\frac{p_{i k}-p_{i L}}{2 \sigma}\right)$,

where $k=R, S, M$. Analogously, the demand for $j=R, S$ is:

$D_{i j}\left(p_{i j}, p_{i L}\right)=\mu_{i} \bigcup\left(\frac{1}{2}+\frac{p_{i L}-p_{i j}}{2 \sigma}\right)$.

contrary, the incentive compatibility constraint is said to be slack when prices are set in such a way that consumers of the strong market will strictly prefer a high quality product to a low quality product.

${ }^{11} \mathrm{We}$ add a technical assumption in order to restrict the number of possible cases, thus focusing on the more interesting ones. We assume that a monopolist wants to serve all the customers of type $t_{2}$ and at least one half of type $t_{1}$. This corresponds to the assumption that consumers are not too differentiated horizontally and vertically. As a consequence, in the duopoly case both markets are completely covered.

${ }^{12}$ Also in this case we assume that firms will satisfy the incentive compatibility constraint. 
As already noted, a low-cost firm is not able to offer a product of quality $q_{2}$, and hence it also has to offer a product of quality $q_{1}$ to consumers belonging to the strong market. Since the evaluation of a $t_{2}$-type consumer for a product of quality $q_{1}$ differs from the one of quality $q_{2}$ by an amount equal to $r=u_{22}-u_{21}$, the perceived price of a product of quality $q_{1}$ is $p_{2 S}=p_{S 1}+r$. In other words, $p_{2 S}$ indicates the price adjusted for the quality.

\subsection{Monopoly}

Using equation (2) and (3), we can write down the optimisation problem of the monopolist $L$ :

$$
\max \sum_{i=1,2} D_{i L}\left(p_{i L}\right)\left(p_{i L}-c_{i}\right), \quad \text { s.t. } \quad p_{2 j}-p_{1 j} \leq r .
$$

The monopoly framework produces a wide range of cases depending on whether it is optimal for the firm to partially or completely cover the markets, and whether or not the incentive compatibility constraint is binding.

In order to simplify the analysis, and considering the more interesting case, we solve the model assuming a partial coverage (at least half) of the weak market and a full coverage of the strong market when IC is binding. Under these assumptions, the optimisation problem of the monopolist becomes as follows:

$$
\max \mu \frac{u_{11}-p_{1 L}}{\sigma}\left(p_{1 L}-c_{1}\right)+(1-\mu)\left(p_{1 L}+r-c_{2}\right) .
$$

The first-order conditions imply that:

$$
p_{1 L}=\frac{1}{2}\left(\left(c_{1}+u_{21}\right)+\sigma \frac{1-\mu}{\mu}\right), \quad p_{2 L}=p_{1 L}+r
$$

Clearly, prices are related to the variables of the model in the following way: a) prices are increasing with costs, b) (all) prices decline when the size of the weak market is large with 
respect to the size of the strong market, c) prices are increasing with the parameters that measure the horizontal heterogeneity.

\subsection{Duopoly}

As we have already assumed, a firm will completely cover the strong market and at least half of the weak market. As a direct consequence, in the duopoly case, both markets are covered. The optimisation problem of firm $L$ is as follows:

$\max \sum_{i=1,2} \mu_{i}\left(\frac{1}{2}+\frac{p_{i k}-p_{i L}}{2 \sigma}\right)\left(p_{i L}-c_{i}\right)$.

We solve the model by assuming that the incentive compatibility constraint is slack, and then we check whether the constraint is satisfied. From the first order conditions we have:

$p_{i L}=\frac{1}{2}\left(c_{i}+p_{i k}+\sigma\right)$,

where $k=R$. By symmetry $p_{i L}=p_{i R}$, and hence:

$p_{i L}=c_{i}+\sigma$.

Consequently, the IC constraint is satisfied when

$c_{2}-c_{1}<r=u_{22}-u_{21}$.

Condition (12) is satisfied when costs are not too different, and when weak and strong markets are sufficiently differentiated. It is worth noting ${ }^{13}$ that if $c_{2}-c_{1}>u_{22}-u_{21}$, then, for a firm, it is better to only produce quality $q_{1}$, as the costs to produce $q_{2}$ are higher than the

\footnotetext{
${ }^{13}$ This result is not specific for the duopoly case, and it also holds for the monopoly case.
} 
advantages coming from the opportunity of charging different prices. Consequently, we assume that condition (12) is always satisfied, and hence IC is never binding in the duopoly case. Intuitively, competition is enough to reduce prices in the strong market more than in the weak market. In the next section, we will show that this is also the same for the asymmetric case, where the competition introduced by a low quality product is enough to limit the prices in the strong market.

\subsection{Asymmetric duopoly}

In the asymmetric duopoly case, we assume that there is a traditional firm $L$, located at 0 , and a low-cost firm, $S$, located at 1 . The low-cost firm has a competitive advantage in costs, but it cannot provide the full range of products (quality $q_{2}$ ).

As in the previous case, we start by assuming that IC is not binding and then we check whether this is indeed the case. As one will see, when firm $S$ sells in the strong market, IC is always slack. Depending on the level of vertical heterogeneity, $S$ may, or may not, be able to sell on the strong market or not. We will focus on the first case. We know that firm $S$, as it cannot provide a high quality product for type $t_{2}$, offers the same quality product for both markets, which corresponds to $q_{1}$. Hence, firm $S$ has only to choose a unique price for the same product offered to consumers of both the weak and strong market. The optimisation problem of firm $S$ is as follows:

$\max \mu\left(\frac{1}{2}+\frac{p_{1 L}-p_{1 S}}{2 \sigma}\right)\left(p_{1 S}-c_{0}\right)+(1-\mu)\left(\frac{1}{2}+\frac{p_{2 L}-p_{1 S}-r}{2 \sigma}\right)\left(p_{1 S}-c_{0}\right)$

Note that the price charged by firm $S$ in the strong market is $p_{1 S}$, but it is perceived as $p_{1 S}+r$, as it is adjusted for the expected quality $q_{2}$. The solution to the maximisation problem is:

$p_{1 S}=\frac{1}{2}\left(c_{0}+\sigma+\mu p_{1 L}+(1-\mu)\left(p_{2 L}-r\right)\right)$.

Using (5) we obtain: 
$p_{1 S}=\frac{2}{3} c_{0}+\frac{1}{3} \omega+\sigma, p_{1 L}=\frac{1}{3} c_{0}+\frac{1}{2} c_{1}+\frac{1}{6} \omega+\sigma, p_{2 L}=\frac{1}{3} c_{0}+\frac{1}{2}\left(c_{2}+r\right)+\frac{1}{6} \omega+\sigma$,

where $\omega=\mu c_{1}+(1-\mu)\left(c_{2}-r\right)$.

From equation (15), we have that $p_{2 L}-p_{1 L}=\frac{1}{2}\left(c_{2}-c_{1}+r\right)$. This is the same result as for the duopoly case. Under condition (12), the incentive compatibility constraint is not binding. Moreover, it is worth mentioning that this result does not require that $c_{0} \leq c_{1}$, and hence it refers to each situation where there is asymmetric competition, and not only to those situations where the traditional player competes with an opponent characterised by a competitive advantage in costs. It is interesting to analyse what happens to the market shares of $S$ in the two markets:

$$
\begin{aligned}
& M S_{1 S}=D_{1 S}\left(p_{1 S}, p_{1 L}\right) / \mu=\frac{1}{2}+\left(\frac{1}{2} c_{1}-\frac{1}{3} c_{0}-\frac{1}{6} \omega\right) /(2 \sigma) \\
& M S_{2 S}=D_{2 S}\left(p_{1 S}, p_{2 L}\right) /(1-\mu)=\frac{1}{2}+\left(\frac{1}{2}\left(c_{2}+r\right)-\frac{1}{3} c_{0}-\frac{1}{6} \omega\right) /(2 \sigma) .
\end{aligned}
$$

In Figure 1, we plot the graph of the market share $M S_{1 S}$ and $M S_{2 S}$ as a function of the willingness to pay ratio $t_{1} / t_{2}$ for $\sigma=0.1$ (smooth lines), 0.2 (spotted lines) assuming that $t_{i}=\sqrt{u_{i i}}, c_{i}=u_{i i} / 2, c_{0}=0.75 \cdot u_{11}, \mu=0.7$ and $t_{2}=1$. The horizontal axis is the ratio $t_{1} / t_{2}$. If $t_{1} / t_{2}$ is low, then the weak and the strong market are strongly differentiated, and when $t_{1} / t_{2}$ is close to 1 , there is low vertical heterogeneity. First, the market share of the low-cost firm in the weak market (smooth black line) is weakly affected by its type parameters. Second, it appears that for a low value of $t_{1} / t_{2}$, the product of $S$ is not attractive for the strong market and its market share, $M S_{2 S}$, is very small. When $\sigma=0.1$ (small horizontal differentiation), the competition is intense so that the markets are more polarised. When $t_{1} / t_{2}$ is about 0.32 , firm $L$ retains all of the strong market. 


\section{Figure 1 Market shares of a low cost firm in the weak and strong market}

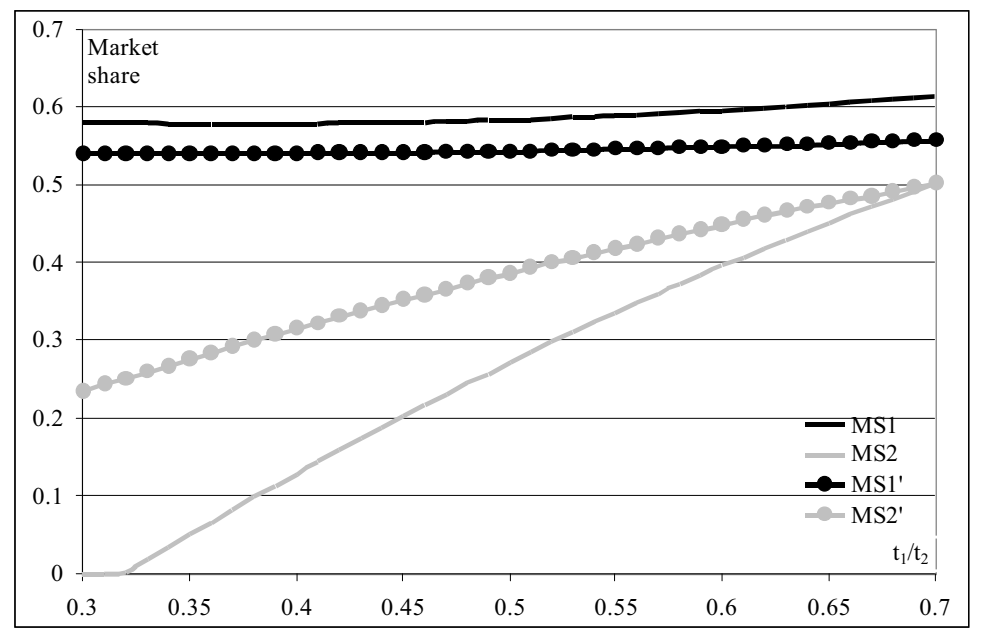

As a final remark, if firm $S$ does not sell products in the strong market, firm $L$ is not free to charge a monopoly price because of potential competition of the products of firm $S$. Practically, firm $L$ charges a price $p_{2 L}$ to exclude firm $\mathrm{S}$, and hence $p_{2 L} \leq p_{1 S}+r+\sigma$.

\subsection{Extension and general outcomes}

The previous set-up can be extended to assess the oligopoly market structure. One of the possible oligopoly situations is the case of three firms: namely two traditional firms located at the extremes of the unitary segment $L$ and $R$, and one low cost firm, $M$, in the centre. When low-cost firms have a positive market share (i.e. the vertical differentiation is not too high), the results are similar to the previous ones:

$p_{1 M}=\frac{2}{3} c_{0}+\frac{1}{3} \omega+\tilde{\sigma}$

and

$p_{1 L}=p_{1 R}=\frac{1}{3} c_{0}+\frac{1}{2} c_{1}+\frac{1}{6} \omega+\tilde{\sigma}, p_{2 L}=p_{2 R}=\frac{1}{3} c_{0}+\frac{1}{2}\left(c_{2}+r\right)+\frac{1}{6} \omega+\tilde{\sigma}$,

where $\omega=\mu c_{1}+(1-\mu)\left(c_{2}-r\right)$.

The equation (18) to (15) differ only for the term $\tilde{\sigma}=\sigma / 2$. Therefore, prices are lower than asymmetric duopoly as the firms can assert less monopoly power (lower horizontal differentiation). Moreover, a strong market price in oligopoly equals the price in symmetric 
duopoly when there is strong vertical differentiation. However there are no cases where oligopolistic prices are higher than duopolistic prices.

In order to highlight the link between the theoretical model and the empirical results, in the next section, we present a short summary of the main outcomes from the previous sections. Table 1 reports the prices per market structure and segment.

Table 1 Prices per market structure and segment

\begin{tabular}{|l|l|l|}
\hline $\begin{array}{l}\text { Market } \\
\text { structure }\end{array}$ & \multicolumn{1}{|c|}{ Economy Price (P1) } & \multicolumn{1}{|c|}{ Business Price (P2) } \\
\hline Monopoly & $p_{1 L}^{\text {mon }}=\frac{1}{2}\left(\left(c_{1}+u_{21}\right)+\sigma \frac{1-\mu}{\mu}\right)$ & $p_{2 L}^{\text {mon }}=p_{1 L}^{\text {mon }}+r$ \\
\hline $\begin{array}{l}\text { Symmetric } \\
\text { Duopoly }\end{array}$ & $p_{1 L}^{\text {sym }}=p_{1 R}^{\text {sym }}=c_{1}+\sigma$ & $p_{2 L}^{\text {sym }}=p_{2 R}^{\text {sym }}=c_{2}+\sigma$ \\
\hline $\begin{array}{l}\text { Asymmetric } \\
\text { Duopoly }\end{array}$ & $\begin{array}{l}\text { asy }=\frac{2}{3} c_{0}+\frac{1}{3} \omega+\sigma \\
p_{1 L}^{a s y}=\frac{1}{3} c_{0}+\frac{1}{2} c_{1}+\frac{1}{6} \omega+\sigma\end{array}$ & $p_{2 L}^{\text {asy }}=\frac{1}{3} c_{0}+\frac{1}{2}\left(c_{2}+r\right)+\frac{1}{6} \omega+\sigma$ \\
\hline $\begin{array}{l}\text { Asymmetric } \\
\text { oligopoly }\end{array}$ & $p_{1 M}^{\text {oly }}=\frac{2}{3} c_{0}+\frac{1}{3} \omega+\tilde{\sigma}$ & $p_{2 L}^{o l y}=p_{2 R}^{o l y}=\frac{1}{3} c_{0}+\frac{1}{2}\left(c_{2}+r\right)+\frac{1}{6} \omega+\widetilde{\sigma}$ \\
& $p_{1 L}^{o l y}=p_{1 R}^{o l y}=\frac{1}{3} c_{0}+\frac{1}{2} c_{1}+\frac{1}{6} \omega+\widetilde{\sigma}$ & \\
\hline & where $\omega=\mu c_{1}+(1-\mu)\left(c_{2}-r\right)$ & \\
\hline
\end{tabular}

The following inequities hold:

1. Weak market: $p_{1 L}^{o l y}<p_{1 L}^{a s y}<p_{1 L}^{s y m}<p_{1 L}^{\text {mon }}$;

2. Strong market: $p_{2 L}^{o l y}<p_{2 L}^{\text {sym }}<p_{2 L}^{a s y}<p_{2 L}^{\text {mon }}$.

Using equation (12) and $\omega=\mu c_{1}+(1-\mu)\left(c_{2}-r\right)$, we have that:

$c_{2}-r \leq \omega \leq c_{1}$.

Combining (21) with the assumption that $c_{0}$ is not too small, we can prove the first two inequalities of equations (19) and (20). In order to prove the last inequalities, we require the assumption of full coverage of the strong market in the monopoly case (Section 3.5). This means that $u_{22}-p_{2 L}^{\text {mon }} \geq \sigma$ or, after substituting for $p_{2 L}^{\text {mon }}$ :

$u_{21}-c_{1} \geq \frac{1+\mu}{\mu} \sigma$. 
Using condition (21) and (22), the results can be easily proved.

Finally, we have shown that the incentive compatibility constraint is binding only for the monopoly case. In the other market structures, the relaxed optimisation problem proved that the IC is never binding. Moreover, we showed that the incentive compatibility constraint is never binding if condition (12) holds, i.e., when the costs of producing two qualities are not too different, and when weak and strong markets are sufficiently differentiated. This means that the price levels are the result of the competitive interaction (relaxed solution). Due to the interdependence between the leisure and the business market, the LCC entry impacts the price levels of the business segment even though it does not offer a full business product. Inequity (19) and (20) are empirically tested in the next section.

\section{Empirical Analysis}

In this section we investigate the pricing strategy of the FSC in relation to the LCC entry. In particular, we empirically test the inequalities (19) and (20), in order to compare the effects of traditional and low cost competition on airfares of the FSC.

\subsection{The database}

Data were collected for selected intra-European, non-stop traffic flows ${ }^{14}$. We restricted the analysis to city-pairs between Italy and the main destinations in the Netherlands, Germany and the UK. About 41 origins and destinations were selected, where one, two, or more carriers offer direct services. We observe the market dominance of the FSCs for most of the city-pairs. In particular, at least $80 \%$ of the market share is covered by one FSC for 11 city-pairs ${ }^{15}$, by one FSC and one LCC for 9 city-pairs, by two FSCs for 15 city-pairs and by two FSCs and one LCC for 5 city-pairs. Only for one city-pair (Milan-London) is 60\% of the market equally covered by two FSCs, and the remaining $40 \%$ of market share is spread over other smaller carriers (including LCCs). We have selected four FSCs: Lufthansa, British Airways, Alitalia and KLM.

\footnotetext{
${ }^{14}$ Analogously, Nero (1998), in order to analyse duopolistic competition, considers only non-stop direct service carriers.
} 
Table 2 Number of observations by destination and carrier

\begin{tabular}{l|cccc|c}
\hline Destinations & Alitalia & $\begin{array}{c}\text { British } \\
\text { Airways }\end{array}$ & KLM & Lufthansa & Total \\
\hline Amsterdam (AMS) & 573 & & 1971 & & 2544 \\
Birmingham (BHX) & & 863 & & & 863 \\
Dusseldorf (DUS) & 632 & & & 560 & 1192 \\
Frankfurt (FRA) & 657 & & & 1634 & 2291 \\
Hamburg (HAM) & 973 & 2083 & & 212 & 212 \\
London (LON) & 612 & 680 & & & 3056 \\
Manchester (MAN) & 443 & & & 1802 & 680 \\
Munich (MUC) & 3890 & 3626 & 1971 & 4665 & 14152 \\
Stuttgart (STR) & & & & & \\
\hline Total & & &
\end{tabular}

All historical and current airfares that have been published in Italy were downloaded from the computer reservation system Galileo ${ }^{16}$. The historical data are necessary in order to compare the fares before and after the LCC entry. The sample contains monthly observations over the period April 2001-July 2003 for any available reservation class of Lufthansa, British Airways, Alitalia and KLM with a total of 14151 airfares. Table 2 presents an overview of the number of observations per destination and carrier.

As previously discussed, yield management enables carriers to segment the market by offering fares with different price levels, rules and conditions. Any fare is linked to a specific reservation class (indicated by a capital letter) that carriers virtually create to allocate the optimal number of passengers on the aircraft. The database contains different numbers of subclasses per carrier that varies from 12 for British Airways to 9 for KLM belonging to two different aircraft cabins: economy and business. Subclasses are for different market segments. Carriers determine their own market segmentation and the relative subclass structure. We attempt to cluster similar subclasses in one unique class mapping. Table 3 presents the 8 identified clusters, of which 6 are in economy class and 2 are in business class.

\section{Table 3 Class mapping between booking sub-classes of carriers}

\begin{tabular}{c|ccccc}
\hline Cabin service & Type of Fare & Alitalia & KLM & British & Lufthansa \\
\hline Economy cabin & Promotional & O-N & V-T & Q-N & W-V \\
& Discounted1 & W-T & L & V-L & Q-H \\
& Discounted2 & Q & K & M & M \\
& Economy1 & B & B & K-H & B \\
& Economy2 & M & S & B-I & B \\
& Unrestricted1 & Y & Z & Y & Y \\
\hline
\end{tabular}

15 The remaining $20 \%$ of the market is covered by one or more different small carriers, including LCCs.

16 The fares have been provided by KLM. 


\section{$\mathrm{C}$}

J J C

The first cluster has been named Promotional, as it includes the lowest published fares of all four carriers. Then there are two discounted classes of tariffs and two economy classes. The three highest fare clusters have been named Unrestricted 1, 2, and 3, as they are addressed mainly to business passengers who require maximum flexibility of travel conditions. In particular, Unrestricted 1 is addressed to the business passenger accommodated in the economy cabin. Table 4 provides some descriptive statistics about the fare clusters.

Table 4 Descriptive statistics of the variable FARE (in Euro)

\begin{tabular}{c|ccccc}
\hline Service cabin & Type of fare & Mean & Std. Dev. & Minimum & Maximum \\
\hline Economy cabin & Promotional & 167 & 33.9 & 99 & 295 \\
& Discounted1 & 276 & 60.1 & 165 & 411 \\
& Discounted2 & 361 & 58.7 & 240 & 494 \\
& Economy1 & 454 & 102.3 & 300 & 732 \\
& Economy2 & 580 & 100.3 & 320 & 838 \\
& Unrestricted1 & 815 & 161.0 & 440 & 1092 \\
\hline Business cabin & Unrestricted2 & 887 & 151.7 & 558 & 1171 \\
& Unrestricted3 & 898 & 207.5 & 574 & 1459 \\
\hline Total & Total & 498 & 255.7 & 99 & 1459 \\
\hline
\end{tabular}

The literature on airfare pricing has identified a number of different factors that affect the determination of the airfare. These factors include, for instance, network structure, type of plane, marketing alliances (Proussaloglou and Koppelman, 1995), hub dominance (Lijesen, Nijkamp and Rietveld, 2000) and competition from other modes of transportation. Vowles (2000) modelled the airfares as depending on geographical factors, such as air distance from the two travel points, or market dominance and specifically on the role of low fare carriers. Similar to the approach of Vowles, we model the airfares as depending on geographical factors, demand factors and market competition. In particular, the market competition has been analysed in two modes: the competition among FSCs, and the competition with LCCs. This distinction is necessary to detect the possible differences between LCC and FSC impact on the airfares. The following variables has been considered:

1. DIST: the air distance from the origin to the destination represents an approximation of the carrier operation costs. We expect that there is a positive impact of the distance (measured in kilometres) on airfares, as any additional kilometre that an aircraft flies is reflected in 
additional costs for the carrier. Data on the distance are collected from the Official Airline Guide.

2. GDP: Gross domestic product per capita of the departure airport catchment's area is an indication of the passenger income and can therefore provide information of the passenger' willingness to pay. The average gross domestic product per inhabitant (in thousands of Euro) of the Italian region where the origin airport is located has been included in this analysis. The source is the EUREGIO database.

3. H: the Herfindal-Hirshman index is a widely accepted indicator for concentration on a market. The index is defined as:

$$
H=\sum_{j} x_{j}^{2} /\left(\sum_{j} x_{j}\right)^{2},
$$

where $x_{j}$ is defined as the output sold by company $j$, and the sum extends over all the FSCs operating in the market. In the airline industry, the output can be the number of passengers or revenues that are generated on a route. Those data are not available at the route level, and therefore the weekly flight frequency has been adopted as output indicator. We limit the $H$ calculation to no-stop frequencies. This choice has no severe consequences for the results, as the market shares of indirect carriers are limited to a maximum of $5 \%$ for all the selected markets. The $H$ index can range from 0 to 1 . It equals 1 when there is only one monopolistic firm in the market, and it tends to zero when the number of firms becomes large. The $H$ index is calculated for FSCs only, as we have decided to capture the impact of LCCs by a different variable. Therefore, this formulation of the $H$ index can be considered as a measure of market concentration of the FSC.

4. LC: the LCC dummy variable is equal to 1 when there is at least one LCC on the market, and 0 otherwise. It can be used to directly test the hypothesis of interdependency among markets. In fact under this assumption, the impact of a low cost entry is significant on economy and business airfares. Within the sample, we have 12 city-pairs with the following LCCs: Ryanair, EasyJet, Basiqair, Volare Web, British Midland, Air Berlin, Virgin Express, Hapag Lloyd Express. 


\subsection{Results}

The database presented above has been used as input for estimating an aviation competition model. The econometric model is specified as follows:

$$
F A R E_{j}=\alpha_{0 j}+\alpha_{1 j} G D P_{j}+\alpha_{2 j} D I S T_{j}+\alpha_{3 j}(1-H)_{j}+\alpha_{4 j} L C_{j}+\alpha_{5 j}(1-H) L C_{j}+\varepsilon_{j}
$$

where GDP and DIST are included as difference from their means. The $H$ index takes the form of $(1-H)$, in order to improve the result interpretation, i.e. in the case of monopolistic situation its impact on the dependent variable FARE is null and the constant represents the monopolistic average price. In any other situation, $(1-H)$ is a measure of the strength of competition. Equation (19) also includes the term $(1-H) L C$ to include the interaction between the FSC and the LCC.

The model has been estimated for the 8 identified clusters by OLS. The estimation results are reported in Table $5^{17}$.

\begin{tabular}{|c|c|c|c|c|c|c|c|c|}
\hline Type of fare & $(\mathrm{CONST})$ & GDP & DIST & $(1-\mathrm{H})$ & $\mathrm{LC}$ & $(1-\mathrm{H}) \mathrm{LC}$ & $\mathrm{R}^{2}$ & Nr. obs. \\
\hline Promotional & $\begin{array}{c}183.12 \\
(112.52)\end{array}$ & $\begin{array}{c}2.60 \\
(9.04)\end{array}$ & $\begin{array}{c}0.01 \\
(5.00)\end{array}$ & $\begin{array}{l}-27.87 \\
(-5.46)\end{array}$ & $\begin{array}{l}-29.05 \\
(-9.54)\end{array}$ & $\begin{array}{l}3.26^{*} \\
(0.46)\end{array}$ & 0.224 & 1436 \\
\hline Discounted 1 & $\begin{array}{c}304.77 \\
(152.37)\end{array}$ & $\begin{array}{c}4.80 \\
(11.69)\end{array}$ & $\begin{array}{c}0.02 \\
(6.24)\end{array}$ & $\begin{array}{l}-76.65 \\
(-11.85)\end{array}$ & $\begin{array}{l}-40.22 \\
(-10.38)\end{array}$ & $\begin{array}{l}38.72 \\
(4.15)\end{array}$ & 0.157 & 2330 \\
\hline Discounted2 & $\begin{array}{c}395.38 \\
(160.56)\end{array}$ & $\begin{array}{c}5.14 \\
(10.90)\end{array}$ & $\begin{array}{c}0.02 \\
(3.99)\end{array}$ & $\begin{array}{l}-90.55 \\
(-12.05)\end{array}$ & $\begin{array}{l}-59.49 \\
(-13.42)\end{array}$ & $\begin{array}{l}78.63 \\
(7.28)\end{array}$ & 0.116 & 1743 \\
\hline Economy1 & $\begin{array}{c}490.42 \\
(154.86)\end{array}$ & $\begin{array}{c}6.93 \\
(10.41)\end{array}$ & $\begin{array}{c}0.06 \\
(12.52)\end{array}$ & $\begin{array}{l}-98.73 \\
(-8.97)\end{array}$ & $\begin{array}{l}-66.07 \\
(-11.88)\end{array}$ & $\begin{array}{l}75.92 \\
(5.13)\end{array}$ & 0.179 & 2934 \\
\hline Economy2 & $\begin{array}{c}606.76 \\
(194.38)\end{array}$ & $\begin{array}{c}3.81 \\
(7.81)\end{array}$ & $\begin{array}{c}0.11 \\
(21.94)\end{array}$ & $\begin{array}{l}-60.41 \\
(-6.41)\end{array}$ & $\begin{array}{l}-62.29 \\
(-8.98)\end{array}$ & $\begin{array}{l}51.01 \\
(3.11)\end{array}$ & 0.176 & 2534 \\
\hline Unrestricted 1 & $\begin{array}{c}892.79 \\
(134.98)\end{array}$ & $\begin{array}{c}5.55 \\
(4.33)\end{array}$ & $\begin{array}{c}0.33 \\
(29.48)\end{array}$ & $\begin{array}{l}-225.44 \\
(-12.44)\end{array}$ & $\begin{array}{l}-45.85 \\
(-4.03)\end{array}$ & $\begin{array}{l}59.66 \\
(2.30)\end{array}$ & 0.526 & 1375 \\
\hline Unrestricted 2 & $\begin{array}{l}977.35 \\
(113.80)\end{array}$ & $\begin{array}{c}7.46 \\
(5.56)\end{array}$ & $\begin{array}{c}0.36 \\
(26.18)\end{array}$ & $\begin{array}{c}-189.04 \\
(-8.15)\end{array}$ & $\begin{array}{l}-74.88 \\
(-5.05)\end{array}$ & $\begin{array}{c}60.48^{*} \\
(1.85)\end{array}$ & 0.541 & 682 \\
\hline Unrestricted3 & $\begin{array}{l}1045.35 \\
(235.30)\end{array}$ & $\begin{array}{c}8.44 \\
(9.42)\end{array}$ & $\begin{array}{c}0.74 \\
(93.88)\end{array}$ & $\begin{array}{c}-128.10 \\
(-9.63)\end{array}$ & $\begin{array}{l}23.55 \\
(2.28)\end{array}$ & $\begin{array}{c}-171.20 \\
(-7.76)\end{array}$ & 0.899 & 1118 \\
\hline
\end{tabular}

\section{Table 5 Regression results for FARE}

t-statistic in brackets; $*=$ not significantly different to zero at $5 \%$ of confidence.

\footnotetext{
${ }^{17}$ Previous researchers had estimatied a similar linear and log model using as the dependent variable the average fares of all subclasses. See, e.g., Brander and Zhang, 1993.
} 
All coefficients have the expected sign and are significant at 5\%, with the exception of the interaction effect $(1-H) L C$ in the first and seventh line. The first column (CONST) captures the average fare that a customer pays when there are neither low LCCs nor other FSCs on the market. As mentioned before, in this case both $(1-H)$ and $\mathrm{LC}$ are equal to 0 . For instance, in the monopoly case, the Promotional fare equals on average $€ 183$ and the Discounted 1 is on average $€ 305$. The second and third columns (DIST and GDP) capture the impact of the distance and income on the fares. The coefficient values of DIST increase, moving from the Promotional1 (0.01) to Unrestricted2 (0.36). This indicates that carriers set their fares in the weaker markets with less regard to costs, and in the stronger markets focusing on costs. For instance, if the destination is 100 kilometres further than the average distance, then the average Promotional fare increases by only $€ 2$ and the Unrestricted 2 fare by $€ 36$.

The latter fare cluster deserves particular consideration. The estimation ${ }^{18}$ in Table 5 shows an explanatory power of DIST that dominates the commercial aspect of GDP and competition variables. This is due to the fact that carriers usually anchor prices of Unrestricted 3 to the IATA published fares. In order to control the IATA effect, and capture the real determinants, we have estimated a different specification of equation (24). The dependent variable is the difference between the official IATA fares and the fares of Unrestricted 3 and the regression variables are the same as those of the previous estimations. The estimation, presented in equation (20), appears to be preferred both in terms of diagnostic results and parameter interpretability ( $\mathrm{R}$-squared $=0.564$ : $\mathrm{t}$-value below the coefficients).

$$
F A R E=1028.5-5.1 G D P+0.11 D I S T-175.18(1-H)+42.58 L C+49.92(1-H) L C
$$

The constant of equation (20) is determined as the average of IATA fares plus the constant of the new estimation (38.5).

Table 5 shows that GDP (as differences from its average) has a positive impact on price levels. Indeed, the coefficient values range from 2.6 for the Promotional fare to 7.46 for the Unrestricted 2 fare. This indicates that, if the regional GDP per capita of the departure airport is

\footnotetext{
18 The fares of International Air Transport Association were determined at an earlier stage than the European market deregulation by a multilateral agreement based on the air distance between the two travel points. Those fares are updated annualy by the world IATA congress.
} 
$€ 1000$ higher than Italian GDP, the fares are $€ 2.6$ for the Promotional class or $€ 7.46$ for Unrestricted 2 higher than the average.

The fourth column presents the coefficients for $(1-H)$. The negative sign of all coefficients indicates that, if the market is less concentrated (lower degree of competition), then the overall fare levels decrease. Alternatively, we can say that when there is only one carrier in the market it can set a fare premium. When a second FSC enters the route, the fares reduction is, on average, around $€ 14$ for the Promotional fare, from $€ 35$ to $€ 50$ to for Discounted 1-2 and Economy 1-2, €110 for the Unrestricted1, €95 for Unrestricted 2 and $€ 88$ for Unrestricted3. The Unrestricted fares show the highest impact. Those are the business-related class where passengers are less price-elastic. We interpret this result as proof that carriers can exert monopoly power.

The fifth column represents the coefficients of the dummy LC, which are all not significantly different from zero with negative sign. Their values range from $-€ 30$ for the promotional up to $-€ 74$ for the Unrestricted 2 with an average of about $-€ 54$. The impact of LCC entrance can be finally determined by also considering the interactive factor (sixth column). In fact, only in the case where the LCC enters a monopolistic market (the interactive effect is null) does the LC coefficient represent the air fares reduction of the FSC. In the case of symmetric duopoly (two FSCs are present in the market), the LCC impact is equal to the LC coefficients minus the interactive coefficients divided by $2^{19}$.

The average fares forecast by the empirical model are presented and compared in Table 6 per class and market structure: monopolistic market (one FSC): symmetric duopoly (two FSCs): asymmetric duopoly (one FSC and one LCC): and asymmetric oligopoly (two FSCs and one LCC).

Table 6 Average fares [ $\epsilon$ ] per class of service and different market structures

\begin{tabular}{l|cccc}
\hline Class of service & Monopoly & $\begin{array}{c}\text { Symmetric } \\
\text { duopoly }\end{array}$ & $\begin{array}{c}\text { Asymmetric } \\
\text { duopoly }\end{array}$ & $\begin{array}{c}\text { Asymmetric } \\
\text { oligopoly }\end{array}$ \\
\hline Promotional & 183 & 169 & 154 & 142 \\
Discounted1 & 305 & 266 & 265 & 246 \\
Discounted2 & 395 & 350 & 336 & 330 \\
Economy1 & 490 & 441 & 424 & 413 \\
Economy2 & 607 & 577 & 544 & 540 \\
Unrestricted1 & 893 & 780 & 847 & 764 \\
Unrestricted2 & 977 & 883 & 902 & 838
\end{tabular}

${ }^{19}$ In the case of asymmetric oligopoly, we assume that $\mathrm{H}$ is equal to 0.5 and $\mathrm{LC}=1$, so the interactive effect is 0.5 . 
The levels decrease as the number of carriers operating in the market increases, i.e. the prices in the monopoly market are higher than those of the duopoly and oligopoly markets for any class of service. The fares are sorted in such a way that seems to respect the inequalities (19) and (20) presented in Section 3.5 for almost all figures. Those inequalities seem to hold for all classes of reservation for both business and the leisure product. Moreover, considering the monopoly as being the benchmark or the starting point from which to compare the other three cases, we can plot the fare differences as in Figure 2. The presence of a traditional competitor (symmetric duopoly) affects the price levels of the two segments (business and leisure) with a different magnitude. In particular, we find that prices decrease about $€ 40$ for leisure classes and about $€ 100$ for business classes. Hence, the competition of traditional carriers seems to significantly reduce the prices of the business fares. In the case of the entry of LCCs (asymmetric duopoly), the impact seems to be homogeneous on all classes of fares, that is a decrease of around $€ 55$.

Figure 2 Fares reduction [E] per class of service and different market competition

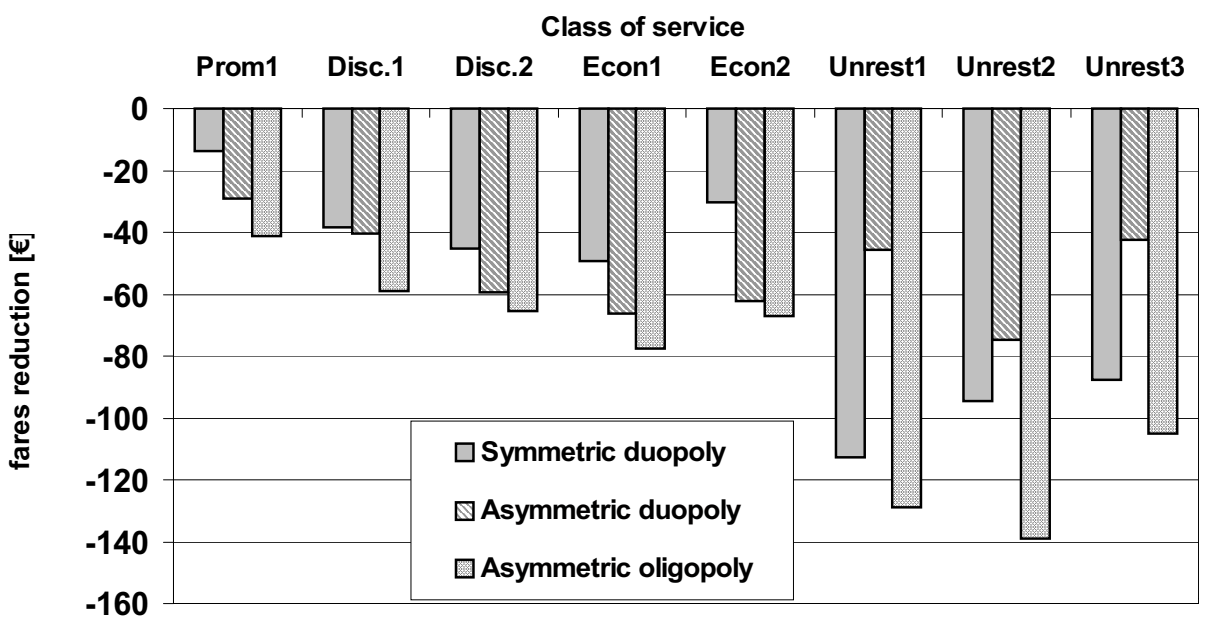

This result corroborates the theoretical assumption of market interdependence between the weak and the strong market. Indeed, the entrance of LCC impacts the price levels of both the business and the leisure segment, even thought the LCCs do not offer a full business service. As a final remark, it is worth noting that the interdependency of markets directly reflects on the 
internal organisation of the marketing division. In a context of competition among FSCs, the assumption of interdependency or separation among markets does not make any difference, as IC is not binding. On the other hand, when we analyse an asymmetric context, even if IC is not binding, pricing strategies on the business market and on the leisure market have to be coordinated. From an organisational perspective the carriers can have team units devoted to the leisure and business market separately, which in the case of LCC competition, these units have to co-ordinate their marketing actions.

These results also suggest a different interpretation of the reduction of prices in the business segment, even if it is ruled out from the theoretical model. Traditional carriers, once they observe that they are losing traffic on the leisure market, are obliged to reduce their fares on that market, but they also need to change all other fares in order to maintain the right "buy up" to satisfy the incentive compatibility constraint.

\section{Conclusions}

This paper has investigated the pricing response of full service carriers (FSCs) when low cost carriers (LCCs) enter the market. We used monthly data on city-pairs from Italy to three European countries (Germany, the UK and the Netherlands) including airfares for four different carriers (Alitalia, Lufthansa, British Airways and KLM). We found that, when a LCC enters a specific route, the direct incumbent firms react by reducing the fares for all available leisure and business fares. We also provide an interpretation in terms of the direct competition of LCC also on the FSC business segment. This point is quite important as it corroborates the assumption that the weak and the strong market are interdependent. On the other hand, competition among two FSCs is characterised by asymmetric behaviour. They strongly compete on the business market and weakly compete on the leisure market. In a context of competition among FSCs, the assumption of interdependency or separation among markets does not make any difference, as the incentive compatibility constraint (IC) is not binding. But, conversely, when we analyse an asymmetric context, even if IC is not binding, pricing strategies on the business market and on the leisure market have to be co-ordinated. As expected, the impact of the LCC on prices is higher when it enters a monopolistic market than a market already characterised by competition.

Finally, the overall results suggest new possible streams of research. The theoretical model results can be empirically tested in terms of market shares and low-cost fares. 
Nevertheless, the specific impact of the product characteristics, both horizontally (departure time, airport access, etc.) and vertically (ground and on-board services, travel conditions for each passenger category, etc.) might be the subjective of future analyses. From a theoretical perspective, it remains open to verify in which duopoly conditions the IC is taken into account by carriers for airfare setting, in addition to the interactive market competition.

\section{Acknowledgements}

The authors would like to thank Anton van Dasler, Aura Reggiani, and participants of the NECTAR meeting in Cergy (November 7-8, 2003) and Amsterdam (19 - 20 March 2004) for their suggestions. Finally, the authors thank KLM Royal Dutch Airlines for providing support in data collection.

\section{References}

Alderighi M, 2004, Non-linear pricing in asymmetric duopoly, mimeo.

Armstrong M, 1996, Multiproduct non-linear pricing, Econometrica, 64: 51-75.

Armstrong $\mathrm{M}$ and J Vickers 2001, Competitive price discrimination, RAND Journal of Economics, 32:579-605.

Berry S 1994, Estimating discrete-choice models of product differentiation", RAND Journal of Economics, 25, 242-262.

Borenstein S and N Rose 1994, Competition and price dispersion in the US Airline Industry, Journal of Political Economy, 102: 653-683.

Borenstein S 1985, Price discrimination in free-entry markets, RAND Journal of Economics, 16:380-397.

Brander JA and A Zhang, 1993, Dynamic Oligopoly behaviour in the airline industry, International Journal of Industrial Organisation, vol. 11 1993, 407-435.

Calem PS and DF Spulber, 1984, Multiproduct two-part tariffs, International Journal of Industrial Organization, 2:105-115.

Carlton DW, 1977, Peak load pricing with stochastic demand, American Economic Review, 67:1006-1010. 
Chang Y and G Williams, 2002, European major airline' strategic reaction to the Third Package, Transport Policy, 9: 129-142.

Clerides, 2003, Price Discrimination with Differentiated Products: Definitions and Identification mimeo.

Dana DJ, 1999a, Using yield management to shift demand when the peak time is unknown, Rand Journal of Economics, 30:456-474.

Dana DJ, 1999b, Equilibrium Price Dispersion Under Demand Uncertainty: the Role of Costly Capacity and Market Structure, RAND Journal of Economics, 30:632-660.

Holmes TJ, 1989, The Effects of Third-Degree Price Discrimination in Oligopoly, American Economic Review, 79:244-250.

Hotelling H, 1929, Sability in competition, Economic Journal, Vol.39: 41-57.

Ivaldi M and D Martimort, 1994, Competition under Non-linear Pricing, Annales d'Economie et de Statistique, 34: 71-114.

Jamilton JH and J-F Thisse, 1997, Non-linear Pricing in Spatial Oligopoly, Economic Design, 2:379-397.

Jensen S, 2001, Price Discrimination and Three-Part Tariffs in a Duopoly, mimeo.

Lijesen MG, P. Nijkamp, P. Rietveld, 2002, Do European Carriers dominate their Hubs? Discussion Papers, Tinbergen Institute, 00-071/3.

McManus B., 2001, Non-linear Pricing in an Oligopoly Market: The Case of Speciality Coffee, mimeo.

Macskási Z, 2003, Non-linear pricing in oligopoly: An Application to the US Mobile Phone Industry, mimeo.

Mussa M and S Rosen, 1978, Monopoly and product quality, Journal of Economic Theory, 18:301-317.

Nero G., 1998, Spatial multi-product pricing: empirical evidence on intra-European duopoly airline market, Applied Economics, 30, 465-475.

Oren SS, SA Smith and RB Wilson, 1983, Competitive non-linear tariffs, Journal of Economic Theory, 29:49-71.

Proussaloglou K and F Koppelman, 1995, Air carrier demand, Transportation 22:371-388.

Rochet, J C and Stole, L A, 2002, Non-linear pricing with random participation, Review of Economic Studies, 69, 277-311. 
Starkie D, 2002, Airport regulation and competition, Journal of Air Transport Management, $8: 62-72$.

Stole L, 1995, Non-linear Prices and Oligopoly, Journal of Economics and Management Strategy, 4: 529-562.

Valletti TM, 2002, Price discrimination and price dispersion in a duopoly, mimeo.

Vowles MT, 2000, The effect of low fare air carriers on airfares in the US, Journal of Transport Geography, 121-128.

Weatherford LR and SE Bodily, 1992, A taxonomy and research overview of perishable-asset revenue management: yield management, overbooking, and pricing, Operations Research, 5, 831-844.

Wilson R, 1993, Non-linear Pricing, New York: Oxford University Press. 